\title{
Evolution of the Microstructure and Mechanical Properties of cBN-Based Cutting Tools with Silicides Compounds as Binder Phase
}

\author{
Kateryna SLIPCHENKO ${ }^{\mathrm{a}, \mathrm{b}, 1}$, Denys STRATIICHUK ${ }^{\mathrm{a}}$, \\ Nadezhda BELYAVINA ${ }^{\mathrm{c}}$, Vladimir TURKEVICH ${ }^{\mathrm{a}}$, \\ Volodymyr BUSHLYA ${ }^{\mathrm{b}}$ and Jan-Eric STÅHL ${ }^{\mathrm{b}}$ \\ ${ }^{a}$ V.N. Bakul Institute for Superhard Materials of NAS of Ukraine, Kyiv 04074, Ukraine \\ ${ }^{b}$ Lund University, Lund 22100 , Sweden \\ ${ }^{c}$ Taras Shevchenko National University of Kyiv, Kyiv 04074, Ukraine
}

\begin{abstract}
Silicide based compounds are widely used for coatings due to their high melting temperature, oxidation resistance and moderate density. Employment of binders based on silicides of transitional metals can provide $\mathrm{cBN}$-based cutting tools with higher chemical stability and better performance. The relationship between phase composition, microstructure and mechanical properties of novel polycrystalline cubic boron nitride $(\mathrm{PcBN})$ materials were investigated. Three series of PcBN samples were made by high pressure high temperature (HPHT) sintering. Silicides of chromium $-\mathrm{CrSi}_{2}$, vanadium - $\mathrm{VSi}_{2}$ and molybdenum $\mathrm{MoSi}_{2}$ were used as a binder phase in each case, while aluminum was introduced to the mixture as an oxygen getter. During HPHT sintering at temperatures above $1850^{\circ} \mathrm{C}$ the formation of borides of binder phase were observed in cases with $\mathrm{VSi}_{2}$ and $\mathrm{MoSi}_{2}$. For system with $\mathrm{CrSi}_{2}$ binder, temperature of boride formation was found to be lower $-1600{ }^{\circ} \mathrm{C}$. Materials with $\mathrm{MoSi}_{2}$ binder phase demonstrated the highest level of microhardness. Performance of materials were investigated in conditions of machining of stainless steel AISI 316L and Inconel 718.
\end{abstract}

Keywords. cBN, silicide, chromium, vanadium, microstructure, PcBN

\section{Introduction}

Since the invention, polycrystalline cubic boron nitride $(\mathrm{PcBN})$ materials are widely used in conditions where diamond based materials or hard ceramics cannot be applied [1]. Especially under high speed machining of iron- and nickel- based alloys [2]. The down side of cBN-based materials is their relatively low resistance to chemical wear [3][5]. In practice, this issue can be partly solved by introducing of additional binder phases like pure metals or ceramic binders. In turn, the type and content of binder phase will

\footnotetext{
${ }^{1}$ Corresponding Author. kateryna.slipchenko@iprod.lth.se
} 
greatly influence the future application and properties of tools. Thus, materials with ceramic binders, namely TiC, TiN or TiCN and content of cBN between 45 and $70 \%$ designate as a BL group (low content of $\mathrm{cBN}$ ), while materials with $\mathrm{cBN}$ content above $80 \%$ in combination with pure metals or ceramic phases corresponds to $\mathrm{BH}$ group(high content of $\mathrm{cBN}$ ).

Comparative study of tool life of different grades of cBN-based materials in conditions of high speed machining of Inconel 718 established superior tool life of materials with low cBN content and ceramic binders [6]. Since that, several studies were performed in order to investigate and improve properties of these materials [7]-[12].

Detailed study of microstructure of commercial PcBN materials with TiCN binder demonstrated presence of typical reaction products such as $\mathrm{TiB}_{2}$ and aluminum compounds ( $\mathrm{AlN}, \mathrm{AlB}_{2}, \mathrm{Al}_{2} \mathrm{O}_{3}$ ) [9], [10], [13], which find good correlation with previous thermodynamic calculations [14]-[16]. While comprehensive study of cBN-based materials with chromium compounds as binder phase established high potential of application of uncommon binder phase materials. Average microhardness of these materials were in a range of $35-40 \mathrm{GPa}$ [17], [18]. Although, investigation of cBNbased materials with vanadium, zirconium compounds as a binders pointed out the importance of chemical stability of binder phase along with high hardness of the tool [12], [19]-[22].

Silicide compounds are widely used as a coatings in a variety of applications due to their high melting temperature, oxidation resistance and moderate density [23]-[25]. Furthermore silicides can be applied for reinforcements for ceramic matrix composites [26]. Therefore, employment of binders based on silicide of transitional metals can provide cBN-based cutting tools with higher chemical stability and better performance.

\section{Experimental details}

Three types of samples were sintered under high pressure and high temperature (HPHT) conditions. Sintering took place at temperature range of $1600-2450{ }^{\circ} \mathrm{C}$, under pressure of $7.7 \mathrm{GPa}$, thus for each series 6 samples were produced. Commercial micro powders of $\mathrm{cBN}, \mathrm{CrSi}_{2}, \mathrm{VSi}_{2}, \mathrm{MoSi}_{2}$ and $\mathrm{Al}$ flakes, were used as the initial materials. The $\mathrm{cBN}$ content in the initial mixtures was 60 vol. $\%, 5$ vol. $\%$ of $\mathrm{Al}$ were introduced to each mixture and remaining volume of sample binder phase $\mathrm{MeSi}_{2}$. Prior to sintering, green bodies were subjected to degasing in vacuum. In order to conduct investigation and test material performance, the well-sintered samples were ground to RNGN090300T cutting insert shape.

Phase composition of initial powder mixtures and sintered samples were conducted by X-ray diffraction analysis STOE STADI MP in $\mathrm{CuK} \alpha$ radiation. Detailed description of software for phase analysis listed in [27]. The study of microstructures was performed on a SEM LEO 1560 equipped with SE2 detector and on a Tescan Mira3 equipped with Oxford EDX detector.

Densities of sintered samples were measured by direct measurements of their sizes and mass. The longitudinal and shear wave sound velocity was measured using Olympus 38D Plus pulse-echo tester for further calculation of elastic modulus [28]. Indentation for microhardness and fracture toughness measurements were done on Vickers Hardness Tester THV-30MDX, with $1 \mathrm{~kg}$ and $5 \mathrm{~kg}$ load on indenter, respectively. Dwell time was kept constant $-15 \mathrm{sec}$. Performance testing was conducted on CNC lathe with application of oil emulsion flood coolant in conditions of high speed longitudinal 
machining of stainless steel SS-EN1.4404 (AISI 316L) and Inconel 718. Cutting parameters for each case listed in Table 1. The average flank wear $(V B)$, was measured using stereo microscope.

Table 1 Cutting parameters.

\begin{tabular}{ccccc}
\hline Workpiece material & $\begin{array}{c}\text { Cutting speed } \\
\left(\mathbf{v}_{\mathbf{c}}\right), \mathbf{m} / \mathbf{m i n}\end{array}$ & $\begin{array}{c}\text { Feed rate }(\mathbf{f}), \\
\mathbf{m m} / \mathbf{r e v}\end{array}$ & $\begin{array}{c}\text { Depth of cut }\left(\mathbf{a}_{\mathbf{p}}\right), \\
\mathbf{m m}\end{array}$ & Time $(\mathbf{t}), \mathbf{s}$ \\
\hline SS-EN1.4404 (AISI 316L) & 300 & 0.15 & 0.3 & 30 \\
Inconel 718 & 200 & 0.1 & 0.3 & 30 \\
\hline
\end{tabular}

\section{Results and discussion}

\subsection{X-ray analysis}

$\mathrm{MoSi}_{2}$ binder: As was confirmed by XRD the initial components of the mixture are $\operatorname{cBN}(a=b=c=3.6172 \AA, F-43 m)$, $\mathrm{MoSi}_{2}(a=b=3.2060 \AA, c=7.8582 \AA$, $I 4 / \mathrm{mmm})$ and WC $(a=b=2.9033 \AA$, $c=2.842 \AA, \quad P-6 m 2)$. Same phase composition was kept in sample sintered at $1600{ }^{\circ} \mathrm{C}$. Presence of tungsten carbide associated with milling process, while absence of aluminum peaks might be due to their weakness and overlapping with other compounds (Figure 1). Increasing of the sintering temperature up to $1850^{\circ} \mathrm{C}$ leads to the formation of molybdenum

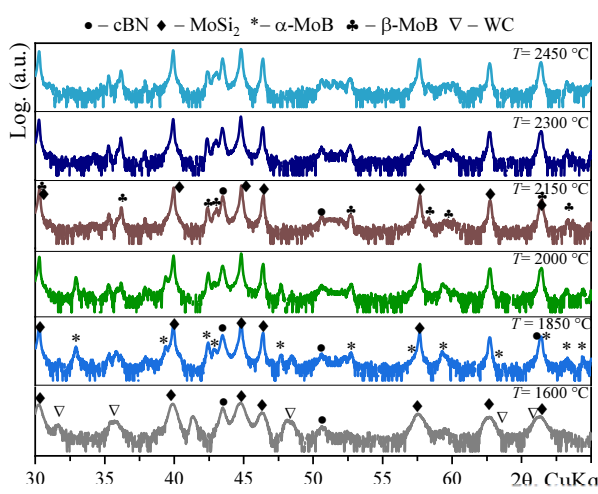

Figure $1 \mathrm{XRD}$ patterns of $\mathrm{cBN}-\mathrm{MoSi}_{2}-\mathrm{Al}$ samples sintered at different temperatures. boride $\alpha-\operatorname{MoB}(a=b=3.1243 \AA, c=16.922 \AA$, I41/amd $)$. It should be noted that, depending on the temperature, the MoB phase exists in two different modifications [29]. Thus, at temperatures above $2150{ }^{\circ} \mathrm{C} \alpha$-MoB transformed into $\beta$-MoB $(a=3.1727 \AA$, $b=8.4560 \AA, c=3.0852 \AA, C m c m)$. Influence of applied temperature and chemical interaction leads to decreasing of $\mathrm{MoSi}_{2}$ lattice volume (Figure 2).

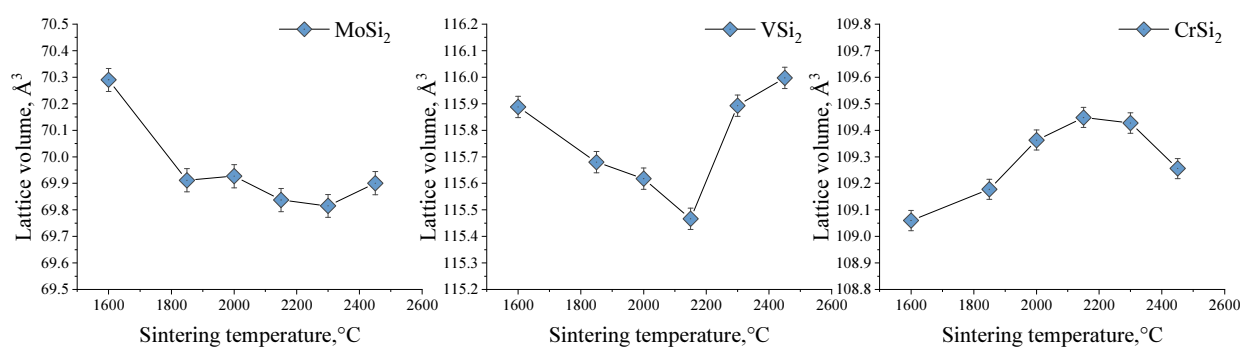

Figure 2 Influence of sintering temperature on lattice volume of silicide phases.

Also, based on Rietveld refinement it can be assumed that at temperatures above $2150{ }^{\circ} \mathrm{C}$ saturation of the $\mathrm{MoSi}_{2}$ lattice with nitrogen occurs, the content of which gradually increases from 1.5 to 4.5 at.\% depending on sintering temperature. Embedded nitrogen is localized in the octahedral pores of the $\mathrm{MoSi}_{2}$ structure (Figure 3) [30]. Not 
all of these nets are occupied by nitrogen atoms, but features noted above may affect on the volume of the unit cell.

$V \mathrm{Si}_{2}$ binder: Weak peaks of tungsten carbide were found on XRD pattern of sample sintered at $1600{ }^{\circ} \mathrm{C}$ (Figure 4 a). Similar to the system with $\mathrm{MoSi}_{2}$ binder, formation of binder phase metal boride occurred at $1850{ }^{\circ} \mathrm{C}, \quad$ namely $\quad \mathrm{VB}_{2} \quad(a=b=2.9980 \AA$, $c=3.0560 \AA, \quad P 6 / \mathrm{mmm})$ was found. Also, at temperatures above $1850{ }^{\circ} \mathrm{C}$ amount of reaction products between aluminum and oxygen become detectable for XRD. This was confirmed by observation of peaks corresponding to $\mathrm{a}-\mathrm{Al}_{2} \mathrm{O}_{3}$ $(a=b=4.7540 \AA, c=12.990 \AA, R-3 c a)$ on relevant XRD patterns on Figure 4 a. At the same time VB $(a=2.9980 \AA, b=8.0920 \AA, c=2.9485 \AA, C m c m)$

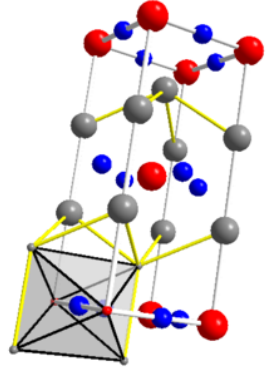

Figure 3 Structure of $\mathrm{MoSi}_{2}$, where red spheras corresponds to Mo, gray $\mathrm{Si}$ and blue $-\mathrm{N}$. was formed instead $\mathrm{VB}_{2}$ in samples sintered at 2000 and $2150{ }^{\circ} \mathrm{C}$. With further increasing of sintering temperature to $2300^{\circ} \mathrm{C}$ lattice parameters of VB decreasing ( $a=2.9927 \AA$, $b=7.9385 \AA, \quad c=2.89310 \AA, \quad C m c m)$. While at $2450{ }^{\circ} \mathrm{C}$ formation of $\mathrm{V}_{2} \mathrm{~B}_{3}$ $(a=3.0340 \AA, b=18.1100 \AA, c=2.9560 \AA, C m c m)$ occurred. Such diversity of vanadium borides can be explained by following assumption: Due to high diffusivity of boron formation of $\mathrm{VB}_{2}$ occurred at $1850{ }^{\circ} \mathrm{C}$. After that, rising of temperature promotes diffusion of $\mathrm{V}$ into $\mathrm{VB}_{2}$ which leads to formation of $\mathrm{VB}$.

$\mathrm{CrSi}_{2}$ binder: As opposed to above described systems the formation of binder metal boride - $\mathrm{CrB}(a=2.9909 \AA, b=7.8661 \AA, c=2.9161 \AA, C m c m)$ already occurred at $1600{ }^{\circ} \mathrm{C}$. Which can be correlated with low melting temperature of $\mathrm{CrSi}_{2}-1490{ }^{\circ} \mathrm{C}$ [29]. In addition, peaks of tungsten carbide was found in this sample (Figure $4 \mathrm{~b}$ ).
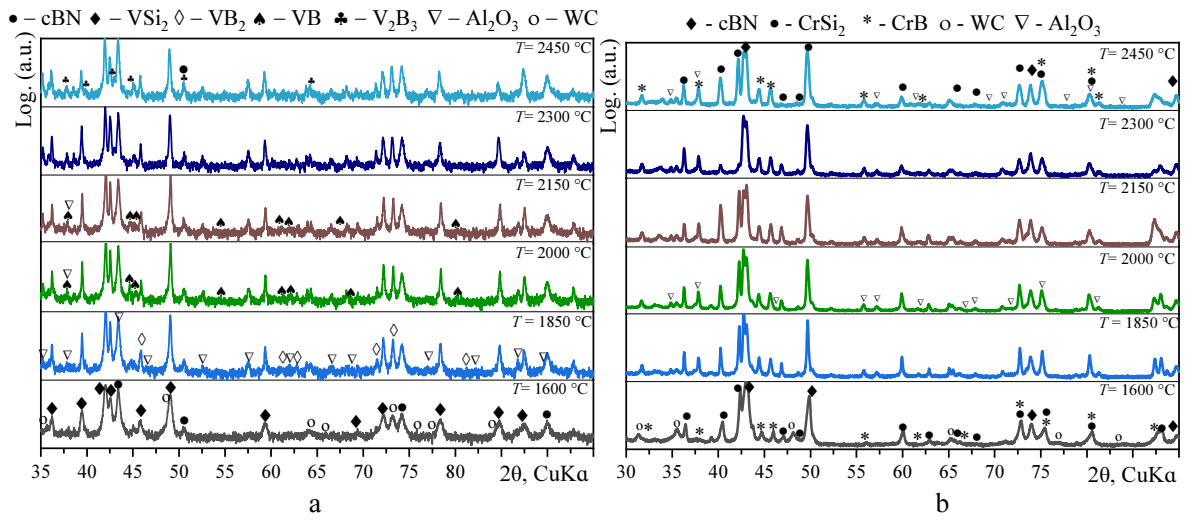

Figure 4 XRD patterns of cBN-VSi $2-\mathrm{Al}$ (a) and $\mathrm{cBN}-\mathrm{CrSi}_{2}-\mathrm{Al}$ (b) samples sintered at different temperatures.

Further increasing of sintering temperature above $2000{ }^{\circ} \mathrm{C}$ leads to increasing of quantity of $\mathrm{a}-\mathrm{Al}_{2} \mathrm{O}_{3}$, what makes it detectable for XRD. Aluminum oxide has same parameters as in case of samples with $\mathrm{VSi}_{2}$. Since presence of tungsten carbide was confirmed by XRD only in sample sintered at $1600{ }^{\circ} \mathrm{C}$ it can be presumed that dissolution of WC into $\mathrm{W}$ and $\mathrm{C}$ occurs [10]. These elements took part in the formation of solid solutions, by replacing chromium atoms in $\mathrm{CrSi}_{2}$ or / and $\mathrm{CrB}$ lattices. If listed above assumption is correct, tungsten work as solute atom in sub lattice of chromium. Thus, according to calculation tungsten content may varies between 0.5 at. $\%$ at $1600{ }^{\circ} \mathrm{C}$ to 
1 at. $\%$ at $2150{ }^{\circ} \mathrm{C}$ for $\mathrm{CrSi}_{2}$ compound. Since atomic radius of $\mathrm{W}$ is slightly higher than $\mathrm{Cr}$ [29], it can cause rising of lattice volume of $\mathrm{CrSi}_{2}$ it mentioned above temperature interval (Figure 2). In turn, boron dissolved from $\mathrm{BN}$ participates in formation of $\mathrm{CrB}$, while nitrogen may diffuse into $\mathrm{CrSi}_{2}$ lattice, which cause its volume decrease at sintering temperatures above $2300^{\circ} \mathrm{C}$.

\section{2. $E D X \& S E M$.}

Figure 5 shows a typical phase distribution in samples sintered at relatively low temperature $-1850{ }^{\circ} \mathrm{C}$. The micrographs were obtained by using secondary electron (SE2) detector. Light gray areas on Figure 5 corresponds to binder phases $\mathrm{MoSi}_{2}$ (a), $\mathrm{CrSi}_{2}$ (b), $\mathrm{VSi}_{2}$ (c) respectively, while dark areas represents $\mathrm{cBN}$ grains. Investigated samples has a uniform distribution of $\mathrm{cBN}$ grains and binder phase. Even at $1850{ }^{\circ} \mathrm{C}$ it is possible to identify areas that proves interactions between components and formation of aluminum oxide or / and metal borides (shown by red arrows).

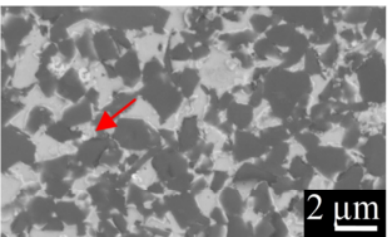

a

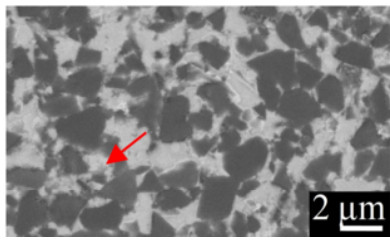

b

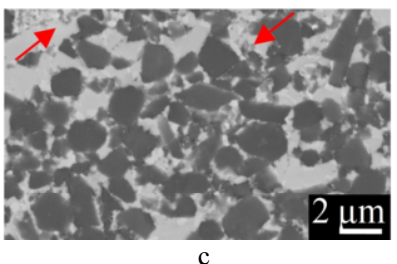

c

Figure 5 Low magnification $\left(15.000^{x}\right)$ images of microstructure of samples sintered at $1850{ }^{\circ} \mathrm{C}$ with $\mathrm{MoSi}_{2}(\mathrm{a}), \mathrm{VSi}_{2}$ (b), $\mathrm{CrSi}_{2}$ (c) binders.

At higher sintering temperature $\left(2150{ }^{\circ} \mathrm{C}\right)$, those areas were found in much larger quantities (Figure 6). Detailed investigation of micrographs pointed out untypical features of the microstructure - round / spherical inclusions in binder phase. Average sizes of these structure features are in the range of 0.1 to $0.3 \mu \mathrm{m}$ and this was applicable for all investigated cases. Aluminum melted during manufacturing process precipitates into the intergrain space and interacts with surface oxides [10], [13]. Observed rounded inclusions is likely to correspond to $\mathrm{Al}_{2} \mathrm{O}_{3}$ (red arrows on Figure 6). Other interesting observation is areas which represents boride phases (blue arrows). So, those samples were subjected to EDX mapping and point analysis (Figure 7).

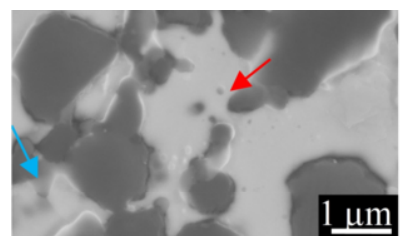

a

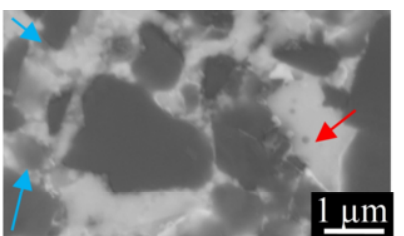

b

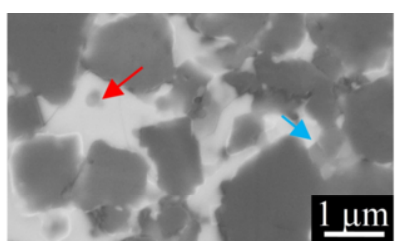

c

Figure 6 High magnification $\left(45.000^{\mathrm{x}}\right)$ images of microstructure of samples sintered at $2150{ }^{\circ} \mathrm{C}$ with $\mathrm{MoSi}_{2}(\mathrm{a}), \mathrm{VSi}_{2}$ (b), $\mathrm{CrSi}_{2}$ (c) binders.

Firstly, as a confirmation of discussed above point analysis show that the dark areas consist of $\mathrm{B}$ and $\mathrm{N}$, confirming $\mathrm{cBN}$ phase distribution. Second, despite the fact that $\mathrm{x}-$ ray phase analysis did not find aluminum or its compounds in samples with $\mathrm{MoSi}_{2}$ presence of aluminum was confirmed by EDX. It was observed that $\alpha-\mathrm{Al}_{2} \mathrm{O}_{3}$ located preferably between or around grains. 
cBN-MoSi $-\mathrm{Al}$

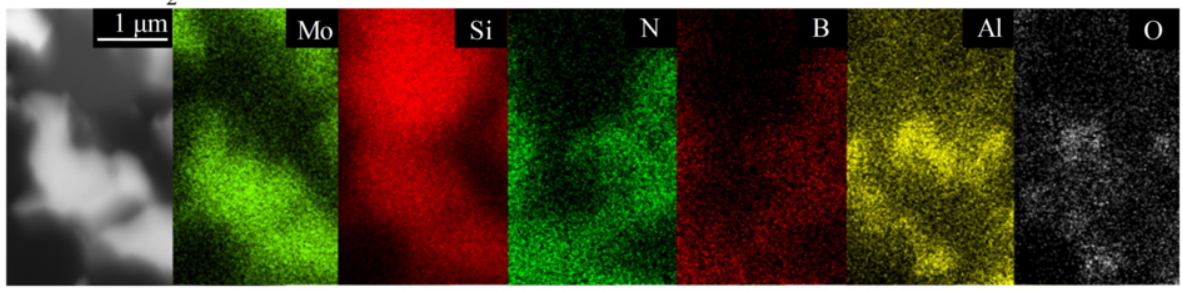

$\mathrm{cBN}-\mathrm{VSi}_{2}-\mathrm{Al}$

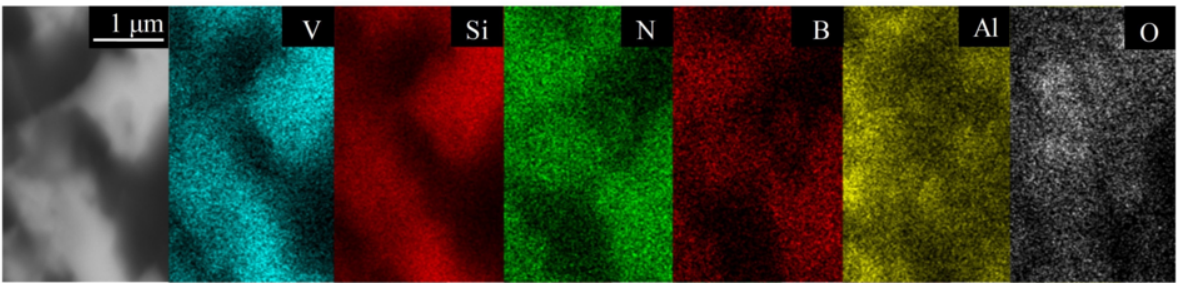

$\mathrm{cBN}-\mathrm{CrSi}_{2}-\mathrm{Al}$

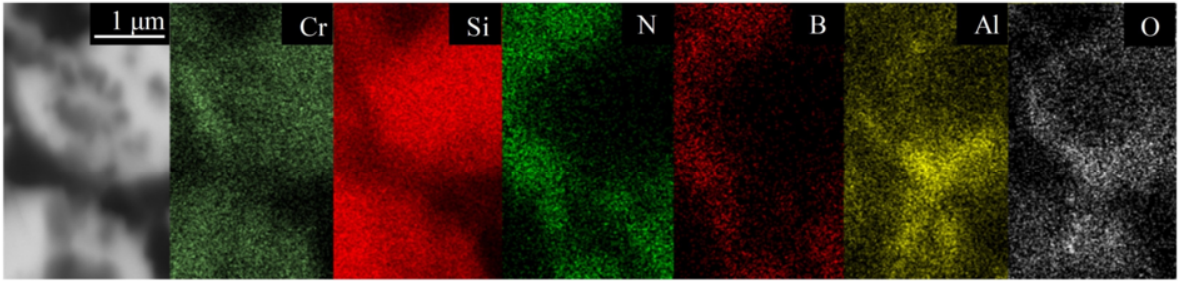

Figure $7 \mathrm{EDX}$ mapping of samples sintered at $2150^{\circ} \mathrm{C}$.

\subsection{Mechanical proprieties}

Density of samples which were subjected only to high pressure action (7.7 GPa) observed to be $20-30 \%$ lower than density of fully sintered samples. While with application of "low" sintering temperature $-1600{ }^{\circ} \mathrm{C}$, density of samples are close to maximum (Figure 8 a).

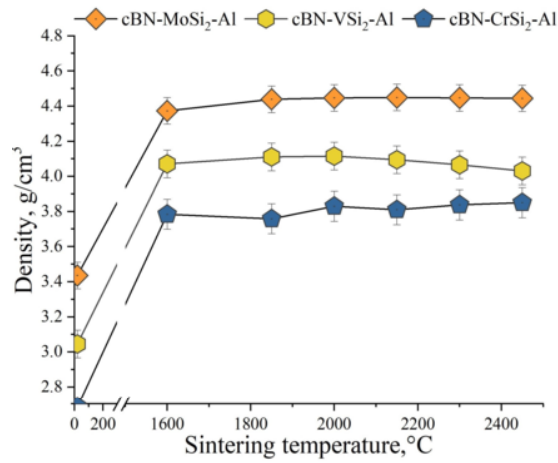

a

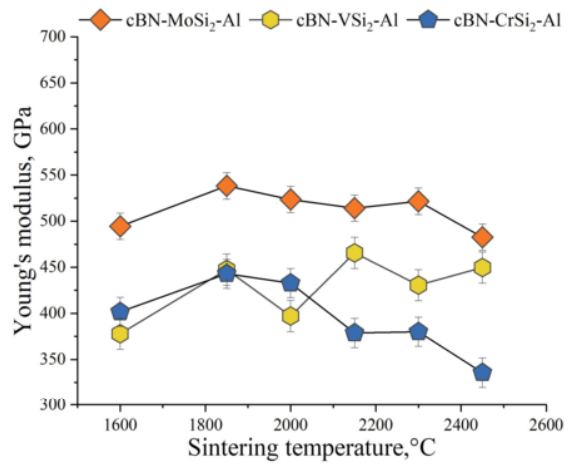

b

Figure 8 Density (a) and Young's modulus (b) of cBN-based materials versus sintering temperature.

However, solid-state reactions continues in a bulk material in the whole sintering range. Samples with $\mathrm{CrSi}_{2}\left(4.91 \mathrm{~g} / \mathrm{m}^{3}\right)$ binder demonstrated the lowest density despites 
that fact that initial density of $\mathrm{VSi}_{2}\left(4.34 \mathrm{~g} / \mathrm{m}^{3}\right)$ compound is the lowest [29]. Densities of vanadium borides $\left(\mathrm{VB}-5.43 \mathrm{~g} / \mathrm{m}^{3}, \mathrm{VB}_{2}-5.06 \mathrm{~g} / \mathrm{m}^{3}\right)$ which were formed in system with $\mathrm{VSi}_{2}$ binder are slightly lower than density of $\mathrm{CrB}\left(6.05 \mathrm{~g} / \mathrm{m}^{3}\right)$ which formed in case of $\mathrm{CrSi}_{2}$ binder. For this reason, the overall density of the system could be related to volume of new phases. In addition, it should be mention that diversity of newly formed borides were found only in the system with $\mathrm{VSi}_{2}$ binder.

The trend of Young's modulus with vs sintering temperature found a good correlation with changes in phase composition (Figure $8 \mathrm{~b}$ ). Thus, Young's modulus increases in temperature range $1600-1850{ }^{\circ} \mathrm{C}$ where interaction either have not started yet or the volume of reaction products is low (i.e. the $\mathrm{CrSi}_{2}$ binder). The value of Young's modulus of systems with $\mathrm{MoSi}_{2}$ and $\mathrm{CrSi}_{2}$ starts to decrease at temperatures higher than $1850{ }^{\circ} \mathrm{C}$, which in turn is associated with precipitation of new phases in grain boundaries.

The hardness of initial silicides are relatively low compare to commercially used TiC binder [31]. Among all investigated binders, $\mathrm{MoSi}_{2}$ has the highest microhardness 11.7 GPa. Microhardness of the formed borides is also high - $23 \mathrm{GPa}$ for $\alpha-\mathrm{MoB}$ and 24.5 GPa for $\beta$-MoB [32], which explains why the entire series has a microhardness on slightly higher level among other materials. In the case of $\mathrm{MoSi}_{2}$ binder, the highest value of microhardness was achieved at $1850{ }^{\circ} \mathrm{C}-32 \mathrm{GPa}$, mainly because of formation of $a$ $\mathrm{MoB}$ which complemented the influence of HPHT action. Further increasing of sintering temperature has no positive effect on microhardness and at $2150{ }^{\circ} \mathrm{C}$ this parameter dropped down to $27 \mathrm{GPa}$ which can be associated with phase transformation in MoB.

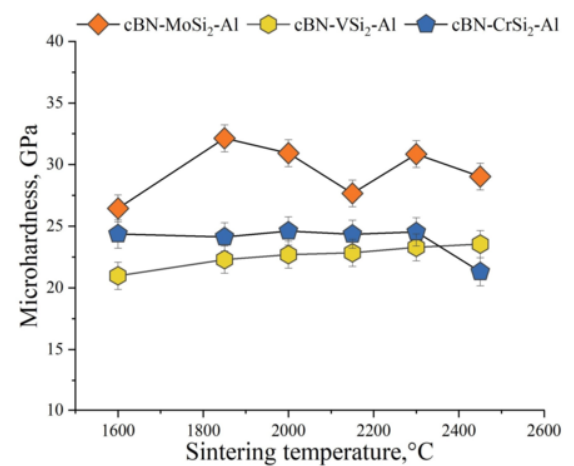

a

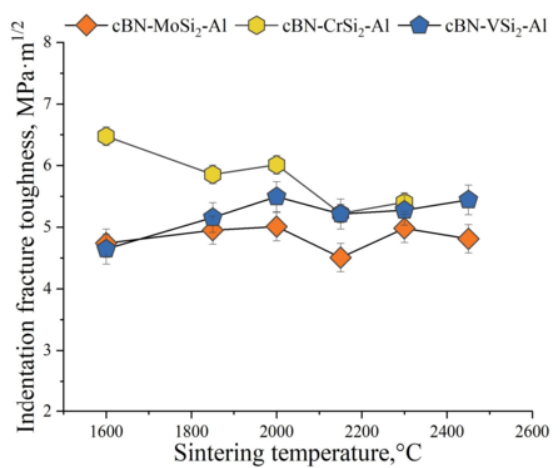

b

Figure 9 Microhardness (a) and indentation fracture toughness (b) of cBN-based materials versus sintering temperature.

Meanwhile for system with $\mathrm{CrSi}_{2}$ binder, microhardness remains practically unchanged with increasing of sintering temperature, it varies around $25 \mathrm{GPa}$ for samples sintered in temperature range $1600-2300{ }^{\circ} \mathrm{C}$. Since the microhardness of $\mathrm{MoSi}_{2}$ and $\mathrm{CrSi}_{2}$ has similar values $11.7 \mathrm{GPa}$ and $11.1 \mathrm{GPa}$ respectively, properties of reaction products become an important factor [32]. In opposite to $\mathrm{MoSi}_{2}$ system, $\mathrm{CrB}$ formed in system with $\mathrm{CrSi}_{2}$, has lower microhardness (11 GPa), compare to MoB [29]. This causes a difference in overall microhardness of the two systems. Dropping the microhardness at $2450{ }^{\circ} \mathrm{C}$ to $21 \mathrm{GPa}$ is caused by recrystallization annealing and reduction of the crystal defect density. Since promotion of movement of dislocations in the material results in its softening [33].

Microhardness of samples with $\mathrm{VSi}_{2}$ binder slightly growing with an increase of sintering temperature (Figure 9). This found good correlation with changes of phase composition - formation of vanadium borides with high microhardness $\left(\mathrm{VB}_{2}-27 \mathrm{GPa}\right)$ 
drive microhardness of samples up but initially low microhardness of $\mathrm{VSi}_{2}-9.4 \mathrm{GPa}$ compensate its grow [29]. That is why microhardness of this system remains the lowest among all studied samples. However silicide compounds usually characterize as brittle materials [34]. Even so, sintered samples demonstrated decent level of fracture toughness. Fracture toughness of samples with $\mathrm{MoSi}_{2}$ and $\mathrm{VSi}_{2}$ binders firstly growth (up to $2000{ }^{\circ} \mathrm{C}$ ) and secondary stays in the range of mistake (Figure 9). While formation of chromium borides drive fracture toughness down [17].

\subsection{Performance testing}

Evaluation of the performance of developed materials were conducted under conditions of longitudinal high speed machining of two different classes of workpiece materials stainless steel SS-EN1.4404 and nickel based alloy Inconel 718 (Figure 10). In case of machining of SS-EN1.4404 the lowest average flank wear was found in system with $\mathrm{MoSi}_{2}$ binder phase, while the highest tool wear was in samples with $\mathrm{CrSi}_{2}$. Samples with $\mathrm{VSi}_{2}$ binder phase demonstrated similar tool wear regardless sintering temperature.

In conditions of high speed machining of Inconel 718 tools with $\mathrm{MoSi}_{2}$ binder also demonstrated the lowest average flank wear, mainly due to their high hardness. In contrast to results of SS-EN1.4404 machining, tool wear in systems with $\mathrm{VSi}_{2}$ and $\mathrm{CrSi}_{2}$ was found to be much more dependent on samples sintering temperature. The highest average flank wear were found in samples sintered at either low $\left(1600-1850^{\circ} \mathrm{C}\right)$ or high $\left(2450{ }^{\circ} \mathrm{C}\right)$ temperatures.

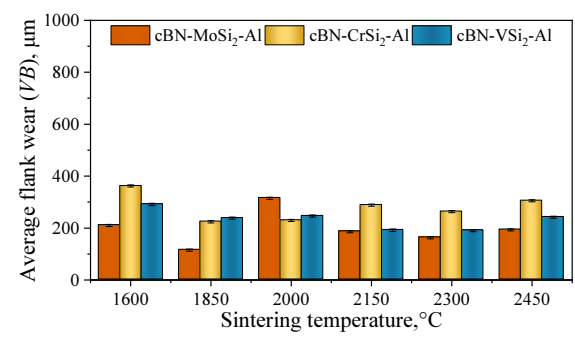

a

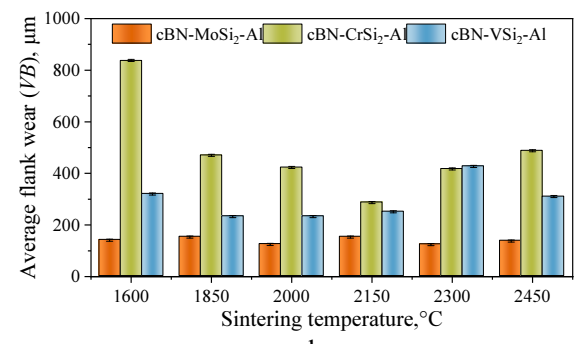

b

Figure 10 Tool wear development when machining SS-EN1.4404 (a) and Inconel 718 (b).

It should be noted that despite the high mechanical properties of the obtained PcBN materials their performance in machining operations of SS-EN 1.4404 and Inconel 718 workpiece materials was found to be significantly lower than the acceptable industrial standard. Previous studies conducted under similar machining conditions using cBN based tools with $\mathrm{TiC}$ binder have shown tool wear below $50 \mu \mathrm{m}$ [35]. Tool wear of commercial CBN170 during machining of Inconel 718, have shown to be less prominent than in case of using Si based binders, despite the fact that cutting speed in current tests was 1.7 times lower [3]. This is most likely caused by the reduced chemical stability of chosen binders and reaction products compared to the commercially used $\mathrm{TiC}$, TiN or $\operatorname{Ti}(\mathrm{C}, \mathrm{N})$ binders.

\subsection{Outlook for future work}

$\mathrm{cBN}-\mathrm{MoSi}_{2}-\mathrm{Al}, \mathrm{cBN}-\mathrm{CrSi}_{2}-\mathrm{Al}$ and $\mathrm{cBN}-\mathrm{VSi}_{2}-\mathrm{Al}$ are all new $\mathrm{PcBN}$ materials which is not used today in commercial cutting applications. Therefore, one of the possibilities 
for future work is to investigate cutting performance of developed materials in machining of martensitic materials, which requires tools with high hardness.

\section{Conclusions}

It was shown that HPHT sintering of cBN-based materials with $\mathrm{VSi}_{2}$ and $\mathrm{MoSi}_{2}$ binder phases took place with interaction between components of the mixture. Formation of borides of binder phase at sintering temperatures above $1850^{\circ} \mathrm{C}$. For system with $\mathrm{CrSi}_{2}$ binder temperature of formation of $\mathrm{CrB}$ was found to be lower- $1600^{\circ} \mathrm{C}$.

In case of $\mathrm{MoSi}_{2}$ binder the highest value of microhardness was achieved at $1850{ }^{\circ} \mathrm{C}$ - $32 \mathrm{GPa}$, mainly because formation of $a-\mathrm{MoB}$ which complemented the influence of HPHT action. All investigated samples demonstrated decent level of fracture toughness, in a range of $5-6 \mathrm{MPa} \cdot \mathrm{m}^{1 / 2}$. Detailed investigation of microstructures pointed out untypical round / spherical inclusions in binder phase, which are likely to correspond to $\mathrm{Al}_{2} \mathrm{O}_{3}$. Results of performance tests emphasize the importance of such parameters as microhardness. Best performance was demonstrated by the materials $\mathrm{MoSi}_{2}$ binder phase, especially in case of machining of nickel based materials. Regardless of the high mechanical properties of the obtained PcBN materials their performance are inferior to commercial tools with Ti-based binders.

\section{Acknowledgement}

This research was supported by European Union's Horizon 2020 Research and Innovation Programme under Flintstone 2020 project (grant agreement No. 689279) and Visby Scholarship by the Swedish Institute (grant number 25946/2018). It is also a part of the Sustainable Production Initiative cooperation between Lund University and Chalmers University of Technology.

\section{References}

[1] F. Klocke, Manufacturing processes 1: turning, milling, drilling, no. 7858. 2011.

[2] R. M'Saoubi et al., High performance cutting of advanced aerospace alloys and composite materials, CIRP Ann. - Manuf. Technol., vol. 64, no. 2, pp. 557-580, 2015.

[3] V. Bushlya, F. Lenrick, J. E. Ståhl, and R. M'Saoubi, Influence of oxygen on the tool wear in machining, CIRP Ann., vol. 67, no. 1, pp. 79-82, 2018.

[4] V. Bushlya, J. Zhou, P. Avdovic, and J. E. Ståhl, Performance and wear mechanisms of whiskerreinforced alumina, coated and uncoated PCBN tools when high-speed turning aged Inconel 718, Int. J. Adv. Manuf. Technol., vol. 66, no. 9-12, pp. 2013-2021, 2013.

[5] K. Sobiyi, I. Sigalas, G. Akdogan, and Y. Turan, Performance of mixed ceramics and CBN tools during hard turning of martensitic stainless steel, Int. J. Adv. Manuf. Technol., vol. 77, no. 5-8, pp. 861-871, 2015.

[6] J.-P. Costes and Y. Guillet, Tool-life and wear mechanisms of CBN tools in machining of Inconel 718 To cite this version : Science Arts \& Métiers ( SAM ), 2015.

[7] S. N. Basu and V. K. Sarin, Oxidation behavior of WC-Co, Mater. Sci. Eng. A, vol. 209, no. 1-2, pp. 206-212, 2002.

[8] J. Angseryd and H. O. Andrén, An in-depth investigation of the cutting speed impact on the degraded microstructure of worn PCBN cutting tools, Wear, vol. 271, no. 9-10, pp. 2610-2618, 2011.

[9] J. Angseryd, E. Coronel, M. Elfwing, E. Olsson, and H. O. Andrén, The microstructure of the affected zone of a worn PCBN cutting tool characterised with SEM and TEM, Wear, vol. 267, no. 5-8, pp. 
1031-1040, 2009.

[10] J. Angseryd, F. Liu, and H. O. Andrén, Nanostructure of a cubic BN cutting tool material, Int. J. Refract. Met. Hard Mater., vol. 49, no. 1, pp. 283-287, 2015.

[11] K. V. Slipchenko et al., The Influence of Sintering Temperature on Phase Composition and Mechanical Properties of cBN-Based Composites with Addition of Vanadium Compounds, Met. Adv. Technol., vol. 41, no. 12, pp. 1559-1610, 2019.

[12] M. P. Bezhenar, G. S. Oleinik, S. A. Bozhko, T. O. Garbuz, and S. M. Konoval, Structure of composites of the cBN-Al-ZrN system produced by high-pressure sintering, J. Superhard Mater., vol. 31, no. 6, pp. 357-362, 2009.

[13] J. Angseryd, M. Elfwing, E. Olsson, and H. O. Andrén, Detailed microstructure of a cBN based cutting tool material, Int. J. Refract. Met. Hard Mater., vol. 27, no. 2, pp. 249-255, 2009.

[14] E. Benko, J. S. Stanislaw, B. Królicka, A. Wyczesany, and T. L. Barr, CBN-TiN, cBN-TiC composites: Chemical equilibria, microstructure and hardness mechanical investigations, Diam. Relat. Mater., vol. 8, no. 10, pp. 1838-1846, 1999.

[15] E. Benko, A. Wyczesany, A. Bernasik, T. L. Barr, and E. Hoope, CBN-Cr/Cr3C2 composite materials: Chemical equilibria, XPS investigations, Ceram. Int., vol. 26, no. 5, pp. 545-550, 2000.

[16] E. Benko et al., Experimental and calculated phase equlibria in the cubic BN-Ta-C system, Ceram. Int., vol. 30, no. 1, pp. 31-40, 2004.

[17] K. Slipchenko, V. Turkevich, I. Petrusha, V. Bushlya, and J.-E. Ståhl, Superhard pcBN materials with chromium compounds as a binder, Procedia Manuf., vol. 25, pp. 322-329, 2018.

[18] K. Slipchenko, I. Petrusha, V. Turkevich, J. Johansson, V. Bushlya, and J.-E. J. E. Ståhl, Investigation of the mechanical properties and cutting performance of cBN-based cutting tools with Cr3C2 binder phase, Procedia CIRP, vol. 72, pp. 1433-1438, 2018.

[19] K. V. Slipchenko, I. A. Petrusha, V. Z. Turkevich, V. M. Bushlya, and J.-E. Stahl, Features of Formation of Structure and Phase Composition During a Reactive Sintering of Cubic Boron Nitride with Compounds of Ti, Cr, V, Metallofiz. I Noveishie Tekhnologii, vol. 40, no. 8, pp. 1081-1091, 2018.

[20] K. V. Slipchenko, I. A. Petrusha, D. A. Stratiichuk, and V. Z. Turkevych, The Influence of VC-Al Additive on Wear Resistance of cBN-based Composites, J. Superhard Mater., vol. 40, no. 3, 2018.

[21] K. V. Slipchenko, V. Z. Turkevich, V. M. Bushlya, and J.-E. Ståhl, cBN based materials with TiNAl binder phase: sintering, structure, properties, Rock Destr. Met. Tools-Tech. Technol. Tool Prod. Appl., vol. 22, pp. 254-260, 2019.

[22] K. V. Slipchenko, I. A. Petrusha, V. Z. Turkevich, V. M. Bushlya, and J.-E. Ståhl, The influence of VC-Al additive content on structure and phase composition of $\mathrm{cBN}$ based superhard materials, Rock Destr. Met. Tools - Tech. Technol. Tool Prod. Appl., vol. 21, pp. 275-284, 2018.

[23] M. McNallan, High Temperature Corrosion and Materials Chemistry: Proceedings of the Per Kofstad Memorial Symposium, 2000.

[24] Z. Yao, J. Stiglich, and T. Sudarshan, Molybdenum Silicide Based Materials and Their Properties, vol. 8. 1999.

[25] S. V Lytovchenko, V. M. Beresnev, V. A. Chyshkala, A. Y. Dmytrenko, U. S. Nyemchenko, and V. V Burkovska, Silicide coatings structure optimization based on multiscale approach, Phys. Surf. Eng., vol. 11, no. 3, pp. 293-298, 2013.

[26] J. J. Petrovic and A. K. Vasudevan, Overview of High Temperature Structural Silicides, MRS Proc., vol. 322, p. 3, 1993.

[27] M. Dashevskyi, O. Boshko, O. Nakonechna, and N. Belyavina, Phase Transformations in Equiatomic Y-Cu Powder Mixture at Mechanical Milling, Metallofiz. i Noveishie Tekhnologii, vol. 39, no. 4, pp. 541-552, 2017.

[28] Elastic Modulus Measurement. [Online]. Available: https://www.olympusims.com/en/applications/elastic-modulus-measurement/.

[29] G. V. Samsonov and I. M. Vinitskii, Refractory Compounds: Handbook, 2nd ed. Moscow: Metallurgy, 1976.

[30] Diamond Crystal and Molecular Structure Visualization. [Online]. Available: https://www.crystalimpact.com/diamond/.

[31] G. V. Samsonov and I. M. Vinitskii, Analysis of Refractory Compounds. Moscow: Metallurgizdat, 1976.

[32] S. P. Murarka, Silicides for VLSI applications. Academic Press, 2012.

[33] I. A. Petrusha, A. S. Osipov, M. V. Nikishina, T. I. Smirnova, Y. A. Mel'niichuk, and P. Klimczyk, Preventive action of silicon nitride at HT-HP sintering of cubic boron nitride, J. Superhard Mater., vol. 37, no. 4, pp. 222-233, 2015.

[34] A. K. Tyagi and S. Banerjee, Materials Under Extreme Conditions: Recent Trends and Future Prospects. Elsevier, 2017. 
[35] K. Slipchenko, I. Petrusha, and V. Turkevich, Physico-mechanical properties of cBN composites with binders based on carbides of Ti, Cr, V in conditions of high-speed machining of AISI 316L, Bull. Natl. Tech. Univ. KhPI coll. Work. Ser. Tech. a Mach. Ind., vol. 6, no. 1282, pp. 3-7, 2018. 